\title{
Factors affecting water availability for high Arctic lichens
}

\author{
T. Inoue ${ }^{1 *}$, S. Kudoh ${ }^{1,2}$, M. Uchida ${ }^{1,2}$, Y. Tanabe ${ }^{1,2}$, M. Inoue ${ }^{3}$, H. Kanda ${ }^{1}$ \\ ${ }^{1}$ National Institute of Polar Research, 10-3 Midori-cho, Tachikawa-shi, Tokyo 190-8518, Japan \\ ${ }^{2}$ Department of Polar Science, The Graduate University for Advanced Studies, 10-3 Midori-cho, Tachikawa-shi, Tokyo 190- \\ 8518, Japan \\ ${ }^{3}$ Faculty of Education and Human Studies, Akita University, 1-1 Tegata-Gakuenmachi, Akita-shi, Akita 010-8502, Japan
}

Lichen symbiosis is a successful nutritional strategy that drives lichen distributions in high Arctic ecosystems. However, the in situ effects of fungal partners (mycobionts) on water availability for the photosynthetic partners (photobionts) and their necessity for survival remains unclear. We investigated the factors creating differences in water availability in high Arctic lichen assemblages using observational and experimental analyses of substrates and thallus morphology in the high Arctic, near Ny-Ålesund, Svalbard $\left(79^{\circ} \mathrm{N}\right)$ during the snow-free season. We used five lichen species found on five substrate types: moss litter, vascular plant litter, mixed litter, biological soil crust (BSC) and gravel. BSC had significantly higher water content than the other substrates; although it had high levels of surface evaporation, BSC took up more ground water. Moreover, the structure of BSC supported greater water retention than the four other substrates in our study, providing the moistest environment for lichens. In fact, $60 \%$ of the surface area of the crustose lichen Ochrolechia frigida, which was mainly distributed on BSC, was in contact with the substrate. In contrast, the four fruticose lichens had larger surface areas than Och frig and roughly $90 \%$ air exposure. Initial rates of absorption and evaporation increased with greater thallus surface area, suggesting that water availability for photobionts is strongly affected by both morphological characteristics and substrate water properties, both of which depend on mycobionts. We conclude that lichens show preferences for both morphologies and substrates that promote autotrophic nutrition in the water-limited glacier foreland of the high Arctic region. 